\title{
Methods, tools, and techniques in toxicovigilance
}

\author{
Authors: Rajaa El Bourichi ${ }^{1}$, Leila Bikjdaouene ${ }^{1}$, Bouchra Benazzouz ${ }^{1}$, Rajae Ramdan $^{1}$, and Omar Akhouayri ${ }^{1}$. \\ ${ }^{1}$ Laboratory of Biology and Health. Ibn Tofail University - Kenitra. Morocco.
}

\begin{abstract}
Toxicovigilance is the active process of identifying and evaluating the toxic risks existing in a community, and evaluating the measures taken to reduce or eliminate them. The operation of toxicovigilance requires the use of methods, tools, and techniques. The objective of this article is to describe the organization of toxicovigilance, to identify their components, and to specify the methods, tools and techniques which are applied to them and are necessary for their operation. To achieve those goals, we based our study on a bibliographic synthesis, where some key references were selected, analysed, and summarised. The results of our study have shown that the performance of a toxicovigilance system requires the mastery and integration of methods, tools, and techniques by trained and experienced staff. Those methods, tools and techniques can be classified into six stages. The study also showed that the practice of toxicovigilance is one of the core tasks of a poison control centres. Our study has shown that Anti-poison and Pharmacovigilance center Morocco constitutes a real observatory in terms of toxicovigilance. It ensures a vigilance and alert function concerning different toxic groups.
\end{abstract}

Keywords. Toxicovigilance; Methods; tools; Techniques; Poison control centers

\section{Introduction}

Poisoning is a significant global public health problem. According to world health organisation, every year thousands of people die worldwide from intentional poisoning, which also causes the loss of millions of years of healthy life. To deal with this problem, the toxicovigilance system intervenes to identify poisoning cases, collect, and analyze data relating to poisoning, process, evaluate, communicate, and alert authorities and the public for preventive actions. Toxicovigilance (TV) is the process of identifying specific circumstances or agents giving rise to poisoning. The practice of toxicovigilance is based on the use of methods, tools and techniques which must be well mastered by qualified and well- trained personnel. Toxicovigilance practice also requires the intervention of poison control centres which are key players as poisoning statistics are essential to define the cause, incidence and severity of poisoning occurring in the general populations. The main goals of this article are to describe the structure and organization of toxicovigilance systems by analyzing the methods, tools and techniques applied to them. This study also highlight the essential contribution of poison control centres in the operation of toxicovigilance, particularly the role of Morocco poison and pharmacovigilance centre (CAPM) which constitutes a real observatory in terms of toxicovigilance, it ensures a vigilance and alert concerning different toxic groups: Poisonous animals (Scorpions; Snakes; Spiders; Poisonous fish, ...); Medication; Gas; Food (including collective food poisoning); Pesticides; House hold cleaning products; Industrial products; Drugs; Cosmetics; Mineral products; Heavy metals. We based our study on a bibliographic synthesis, where some key references were selected, analysed, and summarised.

\section{Organization of toxicovigilance system}

A TV system is created and organized through a legal regulating document (Ministerial decree or Decision) that engages specific tasks for the implementation of a surveillance plan for chemical poisoning. The regulating document also defines communication aspects. The performance of a toxicovigilance system requires the mastery and integration of tools, methods and techniques that can be classified into six steps [1].

\subsection{Data collection}

Data collection is the set of actions consisting in obtaining information on the occurrence of events to generate indicators; it is most often done by spontaneous notification. In toxicovigilance, spontaneous notification corresponds to the declaration or report relating to a poisoning. The purpose of data collection is to design a 
database that is an important source for generating signals[2]. Data collection in toxicovigilance is done from different sources: Health professionals through the reporting of poisoning cases; The public through phone call by a free call number available $24 \mathrm{~h}$ a day, 7 days a week; Cases of intoxication reported to the toxicology laboratory of the poisons control centres; Media monitoring; Documentary monitoring (all scientific publications) [3].

\subsection{Analysis of the collected data}

Case analysis is essential; it is carried out for each notified case before being entered into a database. It takes place in seven stages. First, we must validate the cases, in toxicovigilance, an intoxication is defined as any case of suspected clinical signs or intoxication confirmed by toxicological analyzes. Then we check the completeness of the data. Completeness is the search for as much information as possible, its aim is to establish reliable statistics and to define effective public health strategies. The third step is evaluation of the quality filling of the notification form, the filling must be done according to standards, in toxicovigilance, a well- filled form is type A, a sufficiently completed form is type $\mathrm{B}$, an unusable form for studies is type $\mathrm{C}$, and an unusable form at all levels is type $\mathrm{D}[4]$. The next step is case attributability, It is an assessment of the cause and effect relationship, it must answer the question: is the event (the effect) linked and attributable to an exposure(the cause)? in toxicovigilance, attributability is defined as a scalar probabilistic indicator of the strength the link between exposure to an xenobiotic and the appearance of a symptom, syndrome or disease .In the fifth step we assess the severity of a case, the severity assessment allows to anticipate the risk in order to prepare to face it and/or especially prevent it later, in toxicovigilance, the poisoning severity score (PSS) was developed by the International Chemical Safety Program (IPCS), the European Union Commission (EC), the Association of Centres for Poisons and Clinical Toxicologists (EAPCCT), tested and progressively revised during a project between 1991 and 1994[5],the PSS is a standardized scale for grading the severity of poisoning that allows a qualitative assessment of the morbidity associated with poisoning and better identification of real risks and comparability of data, using the PSS is simple: the most severe symptoms observed are compared to a table containing all the clinical signs by organ/system. The PSS is a severity scale in four classes severity index; None (0): no symptoms, or non-specific symptoms not attributable to intoxication; Minor (1): minor symptoms, transient, spontaneously regressing; Moderate (2): marked or persistent symptoms; Severe (3): severe and life-threatening symptoms; Fatal (4): death. The penultimate step is evaluating the avoidability of the case, the objective of the avoidability assessment is to describe the latent causes for each type of event, identify the most frequent and the most important in order to establish possible lines of security; to assess avoidability we must identify the factors that may have favoured the event using grids to calculate a score or a degree of avoidability. Finally the seventh and the last step is the indepth analysis of the causes, it consists of researching the contributing factors and their prioritization, establishing the chronology of the facts and identifying the immediate causes to better appreciate the avoidability in order to define actions to prevent recurrence through prevention, training [6].

\subsection{Record cases in a database}

A database is a tool for storing and retrieving all the data or information related to an activity. The toxicovigilance databases are structured according to four sections; Patient data: age, sex, history, origin; Product data: name, composition, class, family, presentation, dose, dosage; Data on the event: date, times (onset of notification symptoms), symptomatology, circumstances, location, environment, treatments, evolution; Data on the notified: type of notified (health professional, public, industrial), institution, date and time of declaration, telephone number, e-mail address. For Entering cases, several media were used; currently, the entry is made on an entry mask created from the Epidata software then the database thus constructed is exported to the Excel application. A more efficient system is used (Toxiflow $\left.{ }^{\circledR}\right)$. The recorded data is regularly analyzed to identify trends and generate health signals. For Toxicovigilance, the analysis is carried out using the Epi info software [7].

\subsection{Signal generation}

A signal is defined as information which can reveal an alert situation, the level of precision of which is insufficient and which needs to be validated, confirmed and completed .Generation signal can be done in two ways: The first way is qualitative generation, following receipt of significant cases (by their severity and / or their frequency); The second way is quantitative generation, through regular analysis of the database and at an appropriate pace using statistical methods .In Toxicovigilance, the signal is detected rather qualitatively based on the analysis of the severity, the novelty (the toxicant of the circumstance, the geographical characteristics, the age group, propagation capacity, etc.), but also quantitatively based on the frequency of the event [8].

\subsection{Validation of signals in Alerts}

The validation of the signal makes it possible to ensure its nature, its origin, and its quality. It also ensures that there has been no change in data entry, recording errors, change in a case definition, and change in the reporting system or 
analytical method for laboratory data, which could have falsely been the source of this signal. The criteria for evaluating a signal are ; Severity: number of cases, severity of cases, death, multiple outbreaks; The UnusualUnexpected: region of unusual occurrence, unusual clinical form or severity, mode of transmission or unusual circumstances, new product, product / effect association never observed, etc.; The potential for dissemination: person-to-person transmission (ex: collective food poisoning), link with displacement of populations, etc.; The direct consequences on the patient and the availability of other therapeutic alternatives (if it is a drug, for example); The impact on public health; The ability to respond. Once validated and evaluated, a signal is transformed into an alert which, after risk assessment, is considered a threat to the health of populations and requires a response or adapted actions with a possibly specified degree of urgency. This potential threat must be assessed, and its regional, national, or international scope characterized in order to adapt the measures to manage the event [9].

\subsection{Risk minimization}

Risk minimization is the set of actions that make it possible to prevent or reduce the probability of occurrence of harm linked to exposure to health products, consumer products or environmental agents or to reduce the severity thereof. Should it occur, while ensuring the effectiveness of the measures taken? Before taking action to minimize the risk (manage), it will be necessary to understand (investigate) and properly assess the risk (analyze). A risk analysis consists of three parts linked together by a logical link: Risk assessment, risk management and risk communication. Risk assessment is a methodical approach to synthesize the scientific knowledge available to assess the health effects resulting from exposure of a population or individuals to a substance, an agent, or a dangerous situation. Risk management it is a process of identifying, selecting, implementing and evaluating actions to reduce the risk to human health, the goal is to integrate the actions of reduction in a scientifically valid and economically efficient manner, or risk prevention by considering social, cultural, ethical, political and legal aspects. Risk communication is an iterative process of exchanging information and opinion, throughout the analysis process concerning risk, between individuals, groups, and institutions. Different possible actions to minimize the risks: Taking regulatory measures to restrict the use or withdrawal of the product in question, these are radical measures that make it possible to act effectively on the prejudice; Communication around the risk which aims to warn about a problem, to give an opinion or to update knowledge, the aim is to encourage a change in behaviour or to promote healthy attitudes towards products; Establishment of health risk management strategies by setting up means of assistance in diagnosis and management; Evaluation of risk minimization actions in order to know if the actions taken were successful or not [10].

\section{The role of poisons control centres in toxicovigilance: case of Moroccan poison control and pharmacovigilance centre (CAMP)}

A poisons centre is a specialized unit that advises on, and assists with, the prevention, diagnosis, and management of poisoning. The structure and function of poisons centres varies around the world, however, at a minimum a poisons centre is an information service. Some poisons centres may also include a toxicology laboratory and/or a clinical treatment unit [11].

The CAPM (Morocco poison control and pharmacovigilance centre),officially created in 1989 , is a public utility institution mandated by the Ministry of Health, responsible for the management of poisoning and adverse effects related to health products at the individual and collective level in Morocco. The CAPM is recognized as a collaborating centre by the WHO (World Health Organization), it constitutes a real toxicovigilance observatory [12].

With the Ministerial circular, cases received since 1980 were computerized for data exploitation. Information was used to establish a picture of the epidemiological profiles of intoxications in Morocco; the creation in 1990 of a free call number, available $24 \mathrm{~h}$ a day, 7 days a week, facilitated the improvement of data collection directly from the population, the University teaching hospital, and private medical services. This facilitated a faster treatment of the declaration and notification process and deeper involvement of all stakeholders of the surveillance system [13]. In 1992, the mission of the PCC was defined in the Ministerial circular $\mathrm{N}^{\circ} 2 \mathrm{DR} / 10$ : the CAPM is the national institution in charge of the management of poisoning issues at the individual and collective levels to decrease the morbidity and mortality due to intoxications. At the same time, it helps to rationalize health budget expenses. Interestingly, the TV system in Morocco has been greatly influenced by the national pharmacovigilance system; indeed, they function in tandem (Figure1) [13].

The establishment of the first national epidemiological profile put into evidence the importance of scorpion bites and envenomation as the leading cause of intoxication in Morocco. For this reason, a more specific surveillance plan was put in place in 2001 to address snake bites issued by introducing a register for scorpion bites and envenomation cases [13].

In its general and specific report for the year 2019, the operating process of toxicovigilance lead by the CAMP was analyzed according to its six stages:

1-Collection of information: It concerned all cases responding to the definition of a case of intoxication. The 
sources of information used for to collect the cases were: Telephone calls to the CAPM's Toxicological Information (IT) unit, Statements by mail from health Professionals, cases collected through surveys carried out by the CAPM, The cases published in the press, The cases of scientific publications, Cases of food poisoning published in the management newsletter epidemiology and the fight against diseases (DELM).The declarations of cases of bites scorpion envenomation (PES) through the specific information system to PES are treated separately. The CAPM received 10,933 reports of poisoning cases during 2019 (excluding PES) [14].

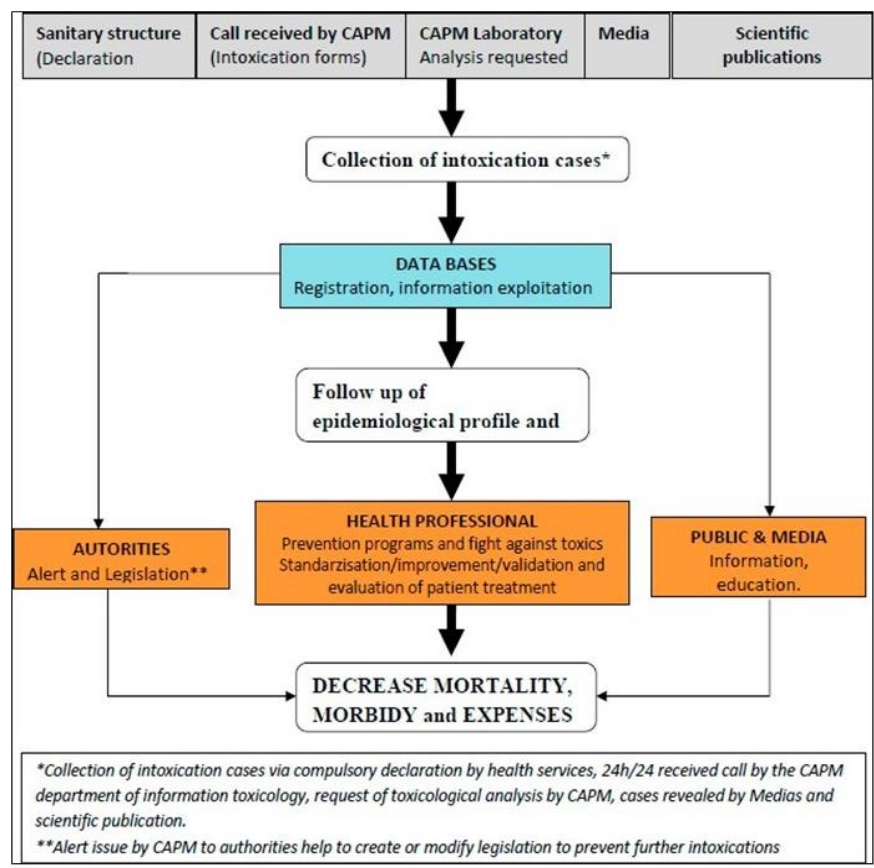

Figure 1: Workflow diagram of the toxicovigilance system in Morocco. [13].

2-Analysis of poisoning cases: Case analysis in TV is an essential step; it is done for each case notified before being entered into a database. The validation of reported cases was done on a day-to-day basis by CAPM doctors. Cases not meeting the definition were excluded. Analysis of the severity according to the Poisoning Severity Score showed that the cases of poisoning were mainly grade 0 (asymptomatic) in $42.2 \%$ [14].

3-Database management (BD), three steps allow the management of the Toxicovigilance System database by the CAMP. The first step is maintaining the database: the cases collected and validated were entered on the Toxiflow software. Quarterly, the entered cases are exported to Excel, compiled, corrected to eliminate errors. The second step is database analysis: it was done quarterly by SPSS software and Excel spreadsheet then at the end of the year. The third step is the development of BD: makes it possible to update the repositories and to review the architecture of BD. The CAPM received a total of 10,933 reports of poisoning cases which were seized and analyzed during the year 2019. This brings the total number of BD cases from 1980 to December 31, 2019 to 213,972 cases, outside of PES. The toxicants most incriminated in the declared cases of poisoning were primarily the medication (33.8\%), followed by gaseous products (15\%) and food products $(12.5 \%)$ (Table I) [9], the year 2019 saw the registration of 50 cases of death, i.e. a mortality of 0.14 per 100,000 inhabitants and a general lethality of $0.5 \%$. [14]

Table II represents the specific lethality according to the toxicants [14].

Table I: Case reporting distribution by product type, CAPM, 2019 [14]

\begin{tabular}{|l|c|c|}
\hline \multicolumn{1}{|c|}{ Toxic family } & Effectives & Percentage \% \\
\hline Medication & 3691 & 33,8 \\
\hline Gaseous products & 1637 & 15,0 \\
\hline Food & 1371 & 12,5 \\
\hline Pesticides & 1028 & 9,4 \\
\hline Household cleaning products & 657 & 6,0 \\
\hline Unknown & 561 & 5,1 \\
\hline Industrial products & 523 & 4,8 \\
\hline Venomous animals & 471 & 4,3 \\
\hline Snakes & 398 & 3,6 \\
\hline Drugs & 252 & 2,3 \\
\hline Plants & 130 & 1,2 \\
\hline Other & 123 & 1,1 \\
\hline Cosmetic products & 87 & 0,8 \\
\hline Foreign bodies & 4 & 0,0 \\
\hline Total & $\mathbf{1 0 9 3 3}$ & $\mathbf{1 0 0 , 0}$ \\
\hline
\end{tabular}

Table II: Specific case fatality rate according to the toxicant family, CAPM, 2018-2019 [14]

\begin{tabular}{|c|c|c|c|c|c|c|}
\hline \multirow{2}{*}{ Toxic Family } & \multicolumn{3}{|c|}{2018} & \multicolumn{3}{|c|}{2019} \\
\hline & Effective & Death & $\begin{array}{c}\text { Specific } \\
\text { lethality \% }\end{array}$ & Effective & Death & $\begin{array}{c}\text { Specific } \\
\text { lethality \% }\end{array}$ \\
\hline Food & 1924 & 3 & 0,2 & 1371 & 2 & 0,1 \\
\hline Venomous animals & 457 & 0 & 0,0 & 471 & 3 & 0,6 \\
\hline Snakes and vipers & 361 & 6 & 1,7 & 398 & 8 & 2,0 \\
\hline Medication & 3071 & 8 & 0,3 & 3691 & 11 & 0,3 \\
\hline Pesticides & 1076 & 22 & 2,0 & 1028 & 10 & 1,0 \\
\hline Plants & 145 & 10 & 6,9 & 130 & 0 & 0,0 \\
\hline Gaseous products & 1358 & 24 & 1,8 & 1637 & 6 & 0,4 \\
\hline Household cleaning products & 489 & 2 & 0,4 & 657 & 0 & 0,0 \\
\hline Cosmetics & 82 & 3 & 3,7 & 86 & 0 & 0,0 \\
\hline Drugs & 241 & 3 & 1,2 & 252 & 1 & 0,4 \\
\hline Industrialproducts & 483 & 0 & 0,0 & 523 & 3 & 0,4 \\
\hline unknown & 296 & 5 & 1,7 & 561 & 4 & 0,7 \\
\hline Other & 216 & 2 & 0,9 & 127 & 2 & 1,6 \\
\hline General lethality & 10199 & 88 & 0,9 & 10935 & 50 & 0,5 \\
\hline
\end{tabular}

4 and 5-Detection of signals and validation of alerts The CAMP proceeded to the detection of Toxicovigilance signals through the analysis of the Database of poisoning cases declared during the year 2019. The sources used for the detection of the signals were: the cases declared to the CAPM, social networks, the press, publications During 2019, the toxicovigilance system in Morocco was able to detect 20 signals, 5 of which were validated as alerts $(25 \%)$. The signals concerning food were in the lead (5) of which none was validated in alert, followed by the signals concerning poisonous animals (4 signals) of which one was validated in alert then the signals concerning 
medication ( 3 signals) of which none has been validated in alert.

6-Risk minimization actions: many actions have been taken by the CAMP, we will only mention a few. These actions can be:

6.1-Regulatory actions: Institution of the obligation: to notify cases of intoxication to the CAPM through Circular $\mathrm{N}^{\circ} 04$ / CAPM / 2019 for the mandatory declaration of all cases of intoxication by health professionals (public, private, semi-public and $\mathrm{CHU}$ ),

6.2-communication actions on the risk: through interventions in media, Participation in interviews, publication of the journal Toxicology Maroc, The WhatsApp mobile application has identified 37 snake specimens, several plants and insects., scientific articles published on the evaluation of the Inoserp MENA antivenom against ophidian envenomations (EO) and on the first case of serious envenomation by Daboia mauritanica treated in Morocco by Inoserp MENA .

6.3-Establishment of health strategies for taking into load of the risk and their application: as the Anti-toxic campaign marked by Launch of the national campaign against scorpion and ophidian envenomations by the Minister of Health (07/01/2019 at the CAPM)., Renewal by the medical provinces of the campaigns against PES [14].

\section{Conclusion}

In a context of globalization and the development of a society of overconsumption, the health approach must imperatively integrate the concept of toxicovigilance to prevent the risks of poisoning.

To master knowledge concerning all the characteristics relating to poisoning, the toxicovigilance system bases its operation on human skills and material resources and adopts tools and methods which are in continuous development.

The detection of signals in Toxicovigilance must be based on the collection of data which is the basis of the functioning of the toxicovigilance system and its performance in terms of quality and quantity. The poison control centres must regularly encourage spontaneous notification and set up mechanisms for active collection of events, to ensure the objective of early detection, and also be based on an evaluation of rigorous risk in order to retain alerts that have a proven impact on public health.

To ensure the effectiveness of a toxicovigilance system it is necessary to respect the three pillars of this system:

-The obligation of the declaration.

-Traceability: Respect for information tracking.

-Mobilization of stakeholders.
1. H. Chaoui, N. Rhalem, A. Soulaymani, R. SoulaymaniBencheikh. Vigilances et sécurité sanitaire, Toxicologie Maroc, 22 (2014).

2. La veille et l'alerte sanitaires en France. Saint-Maurice: Institut de veille sanitaire;( 2011) : http://www.invs.sante.fr

3. R. Afghandous, N. Rhalem, R. Benkirane, A. Mokhtari, R. Soulaymani-Bencheikh. La collecte des cas dans un système de vigilance. Toxicologie Maroc, 22 (2014)

4. S. Benlarbi, H. Chaoui, N. Rhalem, R.S. oulaymaniBencheikh, Analyse des cas dans les vigilances sanitaires, Toxicologie Maroc, 22 (2014)

5. The Prospective Value of the IPCS/EC/EAPCCT Poisoning Severity Score in Cases of Poisoning ( 1998), 36, No.3, Pages215-217

6. Eilstein D., Salines G., Desenclos J-C. Veillesanitaires : outils, fonctions, processus. Revue d'Epidémiologie et de Santé Publique 60(2012). 401-411

7. H. Chaoui, L. Ait Moussa, N. Rhalem, R. Benkirane, L. Ouammi, A. Soulaymani, N. Rhalem, R. Benkirane, R. Soulaymani-Bencheikh. Gestion de bases de données en vigilance sanitaire, Toxicologie Maroc. 22 (2014)

8;9. H. Chaoui, I. Talibi, N. Rhalem, R. Benkirane, A. Soulaymani, R. Soulaymani-Bencheikh. Generation des signaux et des alertes. Toxicologie Maroc 22 (2014)

10. I. Semlali, N. Rhalem, R. Benabdellah, R. SoulaymaniBencheikh. Minimisation des risques dans le cadre de vigilances sanitaires, Toxicologie Maroc, 22 (2014)

11. World Health Organization. WHO/ poisons centres; Available online: https://www.who.int/ipcs/poisons/centre/en/

12. CAPM Présentation $d u$ Centre Antipoison et de Pharmacovigilance $d u$ Maroc. online: http://www.capmsanté.ma

13. P.G. Bertrand, H. Abdel Moniem, and C. Frazzol, Toxicovigilance systems and Practices in Africa, Toxics, 4 (2016)

14. R. Hmimou, N. Rhalem, H. Chaoui, I. Semlali, R. Soulaymani-Bencheikh. Toxicovigilance Rapport General et specifique année 2019, Toxicologie Maroc, 43 (2019)

\section{References}

